\title{
Article
}

\section{Mental Health in Equestrian Sport}

Butler-Coyne, Hannah, Shanmuganathan-Felton, Vaithehy and Taylor, Jamie Alan

Available at http://clok.uclan.ac.uk/22662/

Butler-Coyne, Hannah ORCID: 0000-0001-6778-5605, Shanmuganathan-

Felton, Vaithehy and Taylor, Jamie Alan ORCID: 0000-0002-0619-9992 (2019)

Mental Health in Equestrian Sport. Journal of Clinical Sport Psychology, 13 (3). pp. 405-420. ISSN 1932-9261

It is advisable to refer to the publisher's version if you intend to cite from the work.

http://dx.doi.org/10.1123/jicsp.2018-0002

For more information about UCLan's research in this area go to

http://www.uclan.ac.uk/researchgroups/ and search for <name of research Group>.

For information about Research generally at UCLan please go to

http://www.uclan.ac.uk/research/

All outputs in CLoK are protected by Intellectual Property Rights law, including

Copyright law. Copyright, IPR and Moral Rights for the works on this site are retained by the individual authors and/or other copyright owners. Terms and conditions for use of this material are defined in the policies page.

\section{CLoK}

Central Lancashire online Knowledge www.clok.uclan.ac.uk

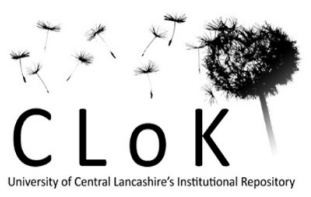


2 Sport participation has well-established physical and mental health benefits (Biddle \&

3 Mutrie, 2008; Daley, 2008). Conversely, and as associated within the athlete

4 population, intense exercise and physical activity has been found to compromise

5 mental health with suggestion of increased experiences of anxiety, depression and

6 burnout (Peluso \& Andrade, 2005). Possibly no surprise, therefore, that an increasing

7 number of high-profile professional sporting personalities (e.g., Clarke Carlisle,

8 former footballer; Ronnie O’Sullivan, snooker player; Dame Kelly Holmes, track gold

9 medallist) are speaking publicly about their experiences of mental health difficulties,

10 the stigma associated with disclosure, and how they have coped in the sporting and

11 competitive environment (BBC Sport, October 2015; Gardner \& Moore, 2006). Low

12 occurrence of mental health difficulties in athletes is often culturally assumed, but this

13 assumption is not supported by any substantive research (Bär \& Markser, 2013). The

14 limited literature available indicates that athletes are equally, if not more, vulnerable

15 to mental health difficulties as the general public (Gulliver, Griffiths, Mackinnon,

16 Batterham, \& Stanimirovic, 2015). Unique emotional 'ups and downs', pressures of

17 competitive sport, stress of daily training, consequences of physical injuries, aging

18 and transition (e.g., leaving and retirement), sport-specific challenges (e.g., team

19 membership, aesthetic determinants) as well as stigma and media scrutiny, all present

20 factors which, if not managed, could lead to particular vulnerability to experiencing

21 mental health difficulties (e.g., eating disorders, Arthur-Camselle, Sossin \&

22 Quatromoni, 2017, Dosil, 2008; obsessive compulsive tendencies, Biggin, Burns \&

23 Uphill, 2017; anxiety, Kamm, 2008; depression and low/negative mood, Nicholls,

24 McKenna, Polman \& Backhouse, 2011, Reardon \& Factor, 2010; general 
various sport-specific demands (physical, psychological and inter/intra personal) can lead to unsafe and unhealthy short-term, yet often effective, strategies (including disordered eating, Shanmugam, Jowett, \& Meyer, 2011; and alcohol abuse, Vamplew, 2012). Unhealthy self-management has been predicted to be an essential element in either precipitating and/or perpetuating pre-existing mental health difficulties (Topolovec-Vranic et al., 2015). In 2014, Mind (a leading mental health charity in the United Kingdom) commissioned research exploring how sports governing bodies and player organisations approach, manage, and respond to mental ill-health within athlete populations across six sports. Findings highlighted various unique challenges negotiated by athletes experiencing mental health difficulties. Stigma and fear of the consequences of disclosure on sporting career were found to often prohibiting talking about the difficulties. Injury or lack of performance, retirement and 'struggling in silence' were all referenced as particular 'pressure points' impacting on athletes' mental health. The research led to the development of the Performance Matters: Mental Health in Elite Sport report, accessible in the public domain. In response, governing bodies from targeted sports initiated a number of changes ranging from 24 hour telephone helplines for athletes (Professional Footballers Association), increased access to counselling and mental health support services for players/athletes (Rugby Players Association; British Athletes Commission), specific mental health training for staff (Premier League) and training inclusion within coaching qualifications (Football Association) (Mind, 2014). Although a positive stride forward, mental health research and practical support within sporting domains where there are unique sporting factors associated with increased risk (i.e., physical harm and/or life threatening/changing injuries) continues to be lacking (Rice et al., 2018).
Commented [HB5]: Reviewer 1.\# Point 10 .

Commented [HB6]: Reviewer 2\#. Point 4. Commented [HB7]: Reviewer 1.\# Point 11 \& Reviewer 2\# Point 7. Commented [HB8]: Reviewer 1\# Point 14. 
52 (Landolt et al., 2017; Thompson \& Nesci, 2016) with many recognised (health) hazards associated within sub-disciplines within the sport (i.e., horse racing and 'making weight', Dolan et al., 2012). Equestrian sport encompasses multiple subdisciplines including dressage, showjumping, eventing, polo, racing, etc. Given the research on elements impacting on athlete mental health, equestrian sportspeople may be a sub-group of athletes particularly vulnerable to elevated risk of experiencing mental health difficulties. In addition to the general pressures all athletes must negotiate, equestrian sub-disciplines appear to have various additional and competing sport-specific stressors. Aesthetic requirements (e.g., weight and appearance) appear to be associated with eating disorder risk for professional jockeys due to sustained attempts to 'make weight' and sustain significantly low weight (Caulfield \&

63 Karageorghis, 2008). Equally, collegiate equestrian athletes may have increased vulnerability to developing eating disorder symptomology due to research findings highlighting distorted perceptions of body image within this population (TorresMcGehee, Monsma, Gay, Minton \& Mady-Foster, 2011). Additionally, the challenging training routines and daily demands of horse ownership can result in significant social and academic sacrifices with Pummell, Harwood \& Lavallee (2008) highlighting potential risks associated with restricted identity development. Equally, the physical and mental demands in equestrian sport and increased vulnerability to physical injury due to the danger associated with the sport are additional stressors for

72 athletes to manage (Dolan et al., 2012; Dosil, 2008; Landolt et al., 2017; Monsma,

73 Gay, \& Torres-McGehee, 2013). A particularly unique element of equestrian sport

74 that is considered fundamental to performance success is the ability of a rider to

75 manage emotions which can influence the horse-rider relationship (McBride \& Mills, 
99

100
2012; Tenenbaum, Lloyd, Pretty, \& Hanin, 2002; Wolframm, Shearman \& Micklewright, 2010). Professional equestrian sportspeople such as Pippa Funnell, Michal Rapcewicz and Mark Enright provide anecdotal evidence of the impact of a rider's emotions, particularly those associated with mental health difficulties on riding ability, decision making, the relationship with the horse, general psychological wellbeing and ultimately performance (Funnell, 2004; Mathieson, 2015).

Commented [HB12]: Reviewer 1\# Point 11.

Commented [HB13]: Reviewer 1\# Point 16 


\section{Method}

A dual approach involving both an anonymous e-survey and a purposive sample of semi-structured interviews was undertaken. The study was approved by the researchers’ University Ethics Committee.

The e-survey was developed to gather a broad range and scope of opinions, whilst the aim of the semi-structured interview was to capture depth of perception.

Both modes of data collection used open-ended questions to gather and explore opinions, understanding and awareness of mental health and psychological wellbeing in equestrian sport.

The qualitative approach to this research was consistent with the researchers' interpretivist epistemological position which is grounded in the premise of sharing knowledge based on descriptions of phenomena rather than pre-existing ideas or frameworks (Creswell, 2014). Demographic information was collected along with eight open-ended questions covering areas of; general understanding, recognition, causes, triggers and impact of mental health difficulties for equestrian sportspeople, and coping strategies and support available for this population. The questions were developed after a review of the literature on mental health and psychological wellbeing in sport whilst also informed by the authors' research experience and expertise in mental health and sport. Example questions include: 'What do the words 'mental health' mean to you?' and 'How do you think mental health difficulties impact upon equestrian sportspeople/athletes?'.

Coach/instructor-athlete and parent-athlete attachment style and relational dynamic have been found in previous research to influence athlete wellbeing, basic psychological need satisfaction (e.g., Davis \& Jowett, 2014; Felton \& Jowett, 2017) and care-seeking responses (Milroy, Hebard, Kroshus \& Wyrick, 2017). With this in 
mind, a holistic systemic approach was adopted to ensure an inclusive understanding of perspectives about mental health and psychological wellbeing in equestrian sport. As such, participants were key individuals involved in the system of an equestrian sportsperson, including the athlete, parent and coach/instructor. The selection of participants was criterion based: individuals over 16 years old who were either/or a competitive equestrian sportsperson, parent(s) or coach/instructor of an equestrian sportsperson and, able to comprehend written or spoken English.

Advertisement of the study and distribution of the e-survey link was facilitated through recruitment drives (over a period of five months; January - May 2016) over social media (Facebook and Twitter), advertisement in an international equestrian magazine, and posters in equestrian colleges/centres.

All participants who completed the e-survey were invited to participate in the interview-based phase of the research through 'opting in' via contacting the lead author as a declaration of interest. Semi-structured interviews were organised through follow-up e-mail correspondence. All interviews were digitally recorded and transcribed verbatim.

\section{Participants}

The final e-survey sample included 155 participants (female, $n=148$ ) with the majority within the age bracket 35-44 years old (23\%) and of a United Kingdom nationality $(81 \%)$. The sample contained individuals from a comprehensive range of equestrian disciplines with various levels of expertise within that discipline (e.g., from amateur to advance/professional Table 1 .), who described themselves as equestrian sportspeople (92\%), parents of an equestrian sportsperson (10\%) or instructor/coach (26\%), with most having over 16 years of experience within equestrian sport (67\%).
Commented [HB19]: Reviewer 1\# Point 18. 

participants ( $75 \%$ female) consisting of equestrian sportspeople (88\%). Forty percent of the participant sample identified as coaches/instructors. The semi-structured interview sample was recruited via the e-survey sample ( $75 \%$ of total semi-structured interview sample) and equestrian colleges/centres (25\%).

\section{Data Analysis} information gathered from the completed e-surveys were analysed using inductive thematic analysis (six phase procedure), a qualitative method for identifying and analysing themes which emerge from the data (Braun \& Clarke, 2006). To ensure consistency of approach, validity and reliability, after interviews were transcribed, they were repeatedly read and coded independently by the lead author and an assistant clinical psychologist. The resultant codes were reviewed by a colleague experienced in qualitative data analysis (Phase 1. \& 2.). Codes were collated into potential themes based on data that appeared repeatedly. Interpretations of all the qualitative data compared, discussed and agreed upon (Phase 3.). Themes were reviewed and further refined, with the development of a thematic map (Figure 1.) when all team members were satisfied that the themes represented the data set (Phase 4. \& 5.). The themes are detailed in this document (Phase 6.).

174 


\section{Results}

Strong thematic commonalities were found regardless of participant expertise or equestrian discipline. Five main themes, 22 first-order themes and 16 second-order themes emerged from the data (Figure 1.). Quotations were selected for inclusion in the paper if considered illustrative of key themes.

\section{INSERT FIGURE 1 HERE}

\section{Theme 1: Emotional Wellbeing in Balance}

The main theme of 'emotional wellbeing in balance' contained four firstorder themes; 'inclusive', 'focused \& organised thoughts', 'positive sense of self' and, 'positive in actions \& interactions'.

Psychological wellbeing and mental health was considered by participants as 'inclusive' and something which all individuals negotiate daily. Fundamental elements were deemed by participants as contributing to, and being a consequence of, sustainable "good mental health". Logical decision making, successful problemsolving, and realistic expectations of self were deemed key factors in demonstrating 'focused \& organised thoughts'. The ability to negotiate a range of emotions, cope with adversity and trust "gut feelings" all contributed to a 'positive sense of self'. Additionally, individuals who are 'positive in actions and interactions' (defined as embracing challenges and opportunities as well as meaningful interaction with others) were considered to maintain psychological wellbeing 'in balance'.

"[mental health is]... being comfortable and confident in your life, happy to be stretched and challenged, meet people, be on your own etc. manage setbacks and take up opportunities." 
202 Theme 2: Emotional Wellbeing Imbalance

204 imbalance' including 'contextual', 'spectrum of imbalance', 'disorganised difficulties' and 'physical health difficulties'. significant 'contextual' factors contributing both positively and negatively to an individual's psychological wellbeing and mental health. Participants referred to a range of 'mental health difficulties' which vary in complexity, severity and intensity, suggestive of a 'spectrum of imbalance'. However, 'disorganised thoughts', typified

212 by issues with problem-solving, reduction in focus, forgetfulness, increased tendency

213 to make "illogical and irrational" decisions, and a 'negative sense of self', inclusive

214 of negative self-belief, low self-esteem and confidence, were indicators of mental health difficulties. 'Personal and professional relationship difficulties' were identified consequences to confusion over change in an individual's behaviour and interaction as a result of an individual struggling to manage their mental health. Additionally, 'physical health difficulties' were perceived as both cause and consequence of problems with psychological wellbeing. Genetic predisposition was considered by some participants to contribute to mental health difficulties, whilst brain dysfunction and susceptibility to illness were perceived to be more as consequences. 


\section{Theme 3: Wellbeing $\underline{\operatorname{Im}}$ balance - Impact on Equestrian Sportspeople} The main theme of 'wellbeing imbalance - impact on equestrian sportspeople' contained five first-order themes; 'negative thoughts, emotions and self-belief', 'perceptions of pressure and judgement', 'unpredictable behaviour and increased risk-taking', 'changes in horse-rider partnership' and, 'inhibited performance, progression and development'.

Sport-specific consequences for those equestrian sportspeople struggling to manage mental health difficulties were characterised by 'negative thoughts, emotions and self-beliefs' about ability and distorted 'perceptions of pressure and judgement' typified by unrealistic goal-setting, reduced focus, concentration and ability to learn, sensitivity to judgements, constructive criticism and taking instruction and, excessively comparing self with others. Both 'negative thoughts, emotions and selfbeliefs' and 'perceptions of pressure and judgement' were considered contributory factors to avoiding competitions, "losing their bottle" (i.e., losing the courage to do something), struggling with motivation, and ultimately, disengagement.

'Unpredictable behaviour and increased risk-taking' including unusual changes in behaviour, recklessness (around themselves, others and with horses), increased falls, alongside identifiable 'changes in the horse-rider partnership' (e.g., horse performance deterioration, decreased confidence displayed by the horse) were considered indicators of an individual struggling with psychological wellbeing. Consequently, 'performance, progression and development' could be inhibited to the point where it could "ruin your career".

"It [mental health difficulties] impacts in every aspect, the way you ride, the way you come into a jump, the route you plan, and the way the horse acts as well, because it is the horse reacting to your body language and how you are so if you are
Commented [HB36]: Reviewer 1.\# Point 9 . 

and effects your whole level of competition."

253

\section{Theme 4: Impact of Equestrian Sport on Wellbeing} psychological wellbeing. unique horse-rider relationship/partnership.

not psychologically prepared for what you are doing, that effects how the horse goes,

Two first-order themes of 'wellbeing imbalance' and 'promotes wellbeing in

balance' emerged from the main theme. Five second-order themes ('horse ownership/industry demands', 'sport/life balance', 'danger of the sport', 'fitting in' and 'pressure and expectations regarding competition and success' were associated with the first-order theme of 'wellbeing imbalance'. With the first-order theme of 'promotes wellbeing in balance' comprising two second-order themes ('increases emotional resilience' and 'therapeutic success and achievement').

Stress factors contributing to 'wellbeing imbalance' were associated with the physical and psychological demands of horse ownership (i.e., working conditions, financial pressures etc.), wider industry issues (e.g., impact of economic downturn; 'fitting in' with peers), negotiating sport/life balance and, the danger of the sport (e.g., illness/loss of horse(s) and colleagues; consequences of accidents and injury). Equally, pressures and expectations (personal and external) and the implication of achievement in competitions (e.g., losing a sponsor, future business etc.) were influential to

\section{Conversely, equestrian sport was considered to actively 'promote wellbeing in}

balance' through the many opportunities to increase self-belief and self-esteem (i.e., success in competition or training). Additionally, negotiating the sporting "ups and downs" was identified as promoting and enhancing emotional resilience. A "therapeutic" element in 'promoting wellbeing in balance' was recognised as the 

ability. However, equestrianism can also have a positive effect on the performance ability and mental state of an individual through achievements."

\section{Theme 5: Regaining Balance} including 'general approaches', 'sport-specific approaches - self', 'sport-specific approaches - instructor/coach', 'bounce-back ability' and, 'sport-specific changes'. Three second-order themes were identified for; 'sport-specific approaches - self' ('seek help \& advice', 'self-management' and 'self-assess and educate'), 'sportspecific approaches - instructor/coach' ('empathetic listening \& open conversation'; 'support, suggest \& advise' and, 'practical support strategies') and 'sport-specific changes' ('culture change', 'reduce stigma \& raise awareness' and, 'accessible specialist input/approaches'). 'general approaches' for any individual struggling to manage mental health difficulties. Self-assessment of the issue, educating oneself and/or actively seeking help and advice from trusted others and personal 'support systems' were recognised as self-perpetuated strategies to understanding and approaching difficulties. Equally, self-management of difficulties through recreational drugs, alcohol, unhealthy eating, 'covering up' the problem, and doing nothing were identified approaches ('sportspecific approaches - self'). Practical techniques including changing and tailoring lesson plans to address approaches to stressors, re-directing goals (e.g., less performance orientated), removing time pressures and sharing stress management 
strategies were potential tactics to support riders in managing mental health difficulties ('sport-specific approaches - instructor/coach'). Specific techniques on how instructor/coaches approach individuals, such as allowing time and space for the individual to talk, asking how someone is feeling, "truly" listening, verbally acknowledging problems and efforts, and signposting to professionals and family, were deemed helpful support strategies. Participants highlighted that those equestrian sportspeople who are managing and negotiating specific mental health difficulties have 'bounce-back ability', described as an extra-ordinary strength and resilience built from personal challenges.

Various 'sport-specific changes' were identified as desirable to enable promotion of psychological wellbeing and aid in reducing stigma. Practical changes suggested were for governing bodies to provide specific regulations regarding work conditions (e.g., fixed pay, accommodation of health and holiday pay etc.), competitions (i.e., prize money, team selection) and sponsorship terms. More openness, disclosure and sympathetic discussion within popular equestrian media about mental health issues authored by specialists and professional equestrian athletes should be encouraged. Increasing the cohesion between the disciplines and reducing emphasis on "winning" were both identified as enabling equestrian sportspeople to feel involved within a supportive community. Participants believed that more sportspecific psychological research and access to specialist input by training of instructors/coaches, or via group training would be of significant value in normalising conversations about psychological wellbeing and mental health.

“...more access to training on how you deal with the emotional side of your client, and your competitor. I must admit that as a riding instructor, I sometimes feel that I would be far better as a trained psychologist as I am dealing with some really 
quite profound emotional issues that some people have got, so I think that might be quite helpful."

\section{Discussion \\ This qualitative study explored the perceptions of a diverse range of equestrian}

sportspeople as to their understanding and awareness of mental health difficulties, the impact on their personal lives and on their sport. Common perspectives were found with five main themes, 22 first-order themes and 16 second-order themes emerging from the data. Two themes ('emotional wellbeing in balance'; 'emotional wellbeing imbalance') offer general insight into awareness and understanding of mental health difficulties and were not specific to equestrian sport. Three sport-specific themes ('wellbeing imbalance - impact on equestrian sportspeople'; 'impact of equestrian sport on wellbeing'; 'regaining balance') provide focus on particular considerations. Mental health and psychological wellbeing was generally recognised as a 'balance' negotiated by everyone, contextually-determined, and ranged on a spectrum varying in complexity and severity. Changes in thought functionality (organised/disorganised), 'sense of self', actions and interaction reflected individual mental health and psychological wellbeing. Physical health issues were seen as being both cause and effect of mental health difficulties.

Unmanaged mental health difficulties were perceived to increase negative beliefs, distort perceptions of pressure and judgement, alter behaviours and reactions, significantly influence changes in horse-rider relationship and thereby generally inhibit performance, progression and development. Physical, psychological and social sport-specific pressures associated with the equestrian lifestyle and competition were also thought to contribute negatively to emotional wellbeing, exacerbate mental health
Commented [HB42]: Reviewer 1\# Point 9 Commented [HB43]: Reviewer 1\# Point 9 
difficulties and affect performance. Conversely, it was acknowledged that involvement in equestrian sport can promote emotional wellbeing through the development of robust resilience, generate positive self-esteem from achievement and provide a unique 'therapeutic' experience in the horse-rider relationship.

\section{Equestrian sportspeople appear to manage mental health difficulties either} through general approaches (e.g., visit GP) and/or sport-specific strategies including 'self-management' techniques and methods led and supported by the ‘instructor/coach'. Self-management strategies were predominantly associated with self-generated assessment, self-education and intervention through unhealthy strategies (e.g., 'do nothing', recreational drugs). Instructor/coach-led strategies tended to be practical support (i.e., re-directing goals; tailoring sessions etc.) and general conversational strategies (e.g., utilising an empathetic and validating approach). Clear sport-specific changes were identified as potential significant steps forward in changing cultural perspectives and reducing stigma and censure with these including education provision, increased media publicity, governing body and professional athlete endorsement and improved access to specialist professionals.

This study provides holistic consideration of the experiences of equestrian athletes but unlike previous research is not exclusive of any particular mental health diagnosis (e.g., eating disorders, Monsma et al., 2013; depression, Hammond, Gialloreto, Kubas, \& Davis, 2013) or coping strategies (i.e., disordered eating, Plateau, McDermott, Arcelus, \& Meyer, 2014; alcohol abuse, Vamplew, 2012). The findings offer additional perspective and insight into potential factors contributing to mental health and wellbeing not only within equestrian sport but with application to sport in general. 


\section{Limitations}

The study obtained a broad international scope of opinion and, as inherent in Commented [HB46]: Reviewer 1\# Point 9. qualitative research, findings are subjective, contextually-bound and not necessarily representative of a universal perspective of equestrian sportspeople. The majority of participants were female, a possible reflection of gender disparity within both the sport (Plymth, 2012) and/or a gender willingness to disclose mental health difficulties both in general population (Martin, Lavalee, Kellmann, \& Page, 2004) and amongst athletes (Hammond et al., 2013).

\section{Clinical and Practice Implications}

Four key clinical and practical implications emerged from the findings. Firstly, and in correspondence with previous sport psychology research (e.g., Gulliver, Griffiths, \& Christensen, 2012; Junge \& Feddermann-Dermot, 2016), the findings underline the importance of promoting greater awareness. Provision of training specifically for instructors/coaches Osffering psycho-education about mental health within the equestrian field and suggestion of practical techniques (e.g., conversational approaches, when to advise referral etc.) would provide meaningful and an empathetic dimension above and beyond that of 'physical skills training' (as advocated by previous research; Plateau et al., 2014). Equally, and as a means of promoting a cultural shift, a mental health module could be produced as part of the syllabus to equestrian training exams, a suggestion also promoted in previous research involving coaches within other elite sport (Biggin et al., 2017; Pensguard \& Roberts, 2000). Raising awareness and educating individuals about mental health difficulties and the importance of psychological wellbeing, aids in promoting open and ongoing discussion with the potential to reduce stigma and promote (healthy) help-seeking 
behaviours and engagement with services and professionals (Biggin et al., 2017; Gulliver et al., 2012; Mind, 2014).

Secondly, increased access to, and publicity about, the best placed psychological professionals specialising in equestrian sport, mental health and psychological wellbeing would promote destigmatisation and potentially early detection and intervention. Additionally, a pro-active approach would prevent confusion and uncertainty for athletes, coaches and parents, as to who to approach whilst also prevent professionals attempting to practice outside of their competencies (Biggin et al., 2017). Publicity could be facilitated through clinics/workshops and articles in popular media whilst also endorsed by governing bodies and sporting professionals. Equally, sports psychologists would benefit greatly by specialist training and/or access to supervision opportunities with clinical psychologists would aid and support towards early detection and access to specialist intervention if required.

Thirdly, as advocated by the findings within this study whilst also research on equine-assisted therapy with various (clinical) population groups (e.g., adults, Bizub, Joy \& Davidson, 2003; children, Schultz, Remick-Barlow \& Robbins, 2007) the horse-rider relationship appears to have specific unique therapeutic benefits in promoting mental health and psychological wellbeing. Equestrian sportspeople may have exclusive opportunity to psychologically benefit from the attachment developed as part of the 'horse-rider' dyad. As such, mental health programmes and training for athletes and instructors/coaches need to ensure some focus on the impact of the horserider dynamic and how to readdress any relational imbalance. 

equestrian sport.

\section{Future directions} groups (e.g., instructors or athletes) would provide insight into the subtle interdiscipline differences in perspectives, so expanding the development of targeted education and intervention.

In promoting psychological wellbeing offered to the equestrian community future specialist training should be augmented with considered intervention techniques, continually reviewed as to applicability, impact, and effectiveness on individual mental health, horse-rider relationship and performance outcomes.

Further exploration into how skills gained from these interventions are incorporated into the daily functioning of an equestrian athlete would inform future provision, policy and research. psychological wellbeing from the perspectives of athletes, instructors/coaches and parents from a diverse range of equestrian sport. The nature of obtaining data via internet communication has enabled international input. The findings offer new insight into sport-specific factors which may promote or compromise the mental health of equestrian athletes. Future research and sport-specific initiatives would 
448 advance techniques in promotion of psychological wellbeing and, prevention, support

449 and recovery of those equestrian athletes experiencing mental health difficulties.

450

451

452 Competing Interests: None.

454 Declaration of Interest: None of the authors of the manuscript have declared any conflict of interest, which may arise from being named as an author on this manuscript. There were no funding sources for this study. 


\section{References}

Arthur-Cameselle, J., Sossin, K., \& Quatromoni, P. (2017). A qualitiative analysis of factors related to eating disorder onset in female collegiate athletes and nonathletes. Eating Disorders, 25(3), 199-215.

Bär, K-J., \& Markser, V.Z. (2013). Sport specificity of mental disorders: the issue of sport psychiatry. European Archives of Psychiatry and Clinical Neuroscience, 263, s205-s210. doi:10.1007/s00406-013-0458-4

BBC Sport (2015, October 5). Clarke Carlisle says some sports 'lagging on mental health'. Retrieved October 18, 2015, from http://www.bbc.co.uk/sport/0/football/34424496

Biddle, S. J.H., \& Mutrie, N., (2008). Psychology of Physical Activity: Determinants, Well-Being and Interventions. (2nd Ed.). London and New York: Routledge

Biggin, I.J.R., Burns, J.H., \& Uphill, M. (2017). An investigation of athletes' and coaches' perceptions of mental ill-health in elite athletes. Journal of Clinical Sport Psychology, 11, 126-147. doi.org/10.1123/JCSP.2016-0017

Bizub, A.L., Joy, A., \& Davidson, L. (2003). "It's like being in another world": demonstrating the benefits of therapeutic riding for individuals with psychiatric disability. Psychiatric Rehabilitation Journal, 26(4), 377-384. doi.org/10.2975/26.2003.377.384

Braun, V., \& Clarke, V. (2006). Using thematic analysis in psychology. Qualitative Research in Psychology, 3, 77-101. doi.org/10.1191/1478088706qp064oa

British Horse Society. Equestrian statistics. Retrieved October 20, 2015, from http://www.bhs.org.uk/our-charity/press-centre/equestrian-statistics 
Caulfield, M.J., \& Karageorghis, C.I. (2008). Psychological effects of rapid weight loss and attitudes towards eating among professional jockeys. Journal of Sports Sciences, 26, 877-883. doi.org/10.1080/02640410701837349

Creswell, J.W. (2014). Research design: qualitative, quantitative and mixed methods approaches. London, UK: Sage.

Daley, A. (2008). Exercise and depression: a review of reviews. Journal of Clinical Psychology in Medical Settings, 15, 140-147. doi 10.1007/s10880-008-9105

Davis, L., \& Jowett, S. (2014). Coach-athlete attachment and the quality of the coachathlete relationship: implications for athlete's well-being. Journal of Sports Sciences, 32(15), 1454-1464. doi.org/10.1080/02640414.2014.898183

Dolan, E., McGoldrick, A., Davenport, C., Kelleher, G., Byrne, B., Tormey, W., Smith, D., \& Warrington, G.D. (2012). An altered hormonal profile and elevated rate of bone loss are associated with low bone mass in professional horse-racing jockeys. Journal of Bone and Mineral Metabolism, 30(5), 534-542. doi $10.1007 / \mathrm{s} 00774-012-0354-4$

Dosil, J. (2008). Eating disorders in athletes. Wiley: England.

Felton, L., \& Jowett, S. (2017). Self-determination theory perspective on attachment, need satisfaction, and well-being in a sample of athletes: a longitudinal study. Journal of Clinical Sport Psychology, 11(4), 304-323.

Funnell, P. (2004). Pippa Funnell: the autobiography. Orion: Great Britain. Gardner, F., \& Moore, Z. (2006). Clinical sport psychology. United States of American: Human Kinetics.

Gulliver, A., Griffiths, K.M., \& Christensen, H. (2012). Barriers and facilitators to mental health help-seeking for young elite athletes: a qualitative study. BMC Psychiatry, 12, 157. doi:10.1186/1471-244X12-157 
Gulliver, A., Griffiths, K.M., Christensen, H., Mackinnon, A., Calear, A., Parsons, A., ...et al. (2012). Internet-based interventions to promote mental health helpseeking in elite athletes: an exploratory randomised controlled trial. Journal of Medical Internet Research, 14(3), 120-137. doi:10.2196/jmir.1864

Gulliver, A., Griffiths, K.M., Mackinnon, A., Batterham, P.J., \& Stanimirovic, R. (2015). The mental health of Australian elite athletes. Journal of Science and Medicine in Sport, 255-261. doi:10.1016/j.jsams.2014.04.006

Hammond, T., Gialloreto, C., Kubas, H., \& Davis, H. (2013). The prevalence of failure-based depression among elite athletes. Clinical Journal of Sport Medicine, 23(4), 273-277. doi:10.1097/JSM.0b013e318287b870

Hughes, L., \& Leavey, G. (2012). Setting the bar: athletes and vulnerability to mental illness [Editorial]. The British Journal of Psychiatry, 200, 95-96. doi: 10.1192/bjp.bp.111095976

Junge, A., \& Feddermann-Demont, N. (2016). Prevalence of depression and anxiety in top-level male and female football players. British Medical Journal Open Sport \& Exercise Medicine, 2, e000087. doi:10.1136/bmjsem-2015-000087

Kamm, R.L. (2008). Diagnosing emotional disorders in athletes: a sport psychiatrists perspective. Journal of Clinical Sport Psychology, 2, 178-201.

Landolt, K., O’Halloran, P., Hale, M.W., Horan, B., Kinsella, G., Kingsley, M., \& Wright, B.J. (2017). Identifying the sources of stress and rewards in a group of Australian apprentice jockeys. Qualitative Research in Sport, Exercise and Health, 9(5), 583-599. doi.org/10.1080/2159676X.2017.1340329

Martin, S., Lavallee, D., Kellmann, M., \& Page, S. (2004). Attitudes toward sport psychology consulting of adult athletes from the United States, United Kingdom 
and Germany. International Journal of Sport and Exercise Psychology, 2, 146160. doi: 10.1080/1612197X.2004.9671738

Mathieson, A. (2015, May 11). Report finds athletes are afraid of admitting mental health problems. Horse \& Hound. Retrieved from http://www.horseandhound.co.uk/news/report-finds-athletes-are-afraid-ofadmitting-mental-health-problems-489555

McBride, S.D., \& Mills, D.S. (2012). Psychological factors affecting equine performance. Bio Medical Council Veterinary Research, 8(180), 1-11. doi.org/10.1186/1746-6148-8-180

Milroy, J.J., Hebard, S., Kroshus, E., \& Wyrick, D.L. (2017). Sport-related concussion reporting and coach-athlete attachment among collegiate studentathletes. Journal of Clinical Sport Psychology, $1-23$. doi.org/10.1123/icsp.2017-0029

Mind (2014). Mental health in elite sport. Retrieved October, 20, 2015, from http://www.mind.org.uk/news-campaigns/campaigns/sport-and-mental-health/ Monsma, E.V., Gay, J.L., \& Torres-McGehee, T.M. (2013). Physique related perceptions and biological correlates of eating disorder risk among female collegiate equestrians. Journal of Athletic Enhancement, 2:2. doi: 10.4172/23249080.1000107.

Nicholls, A.R., McKenna, J., Polman, R.C.J., \& Backhouse, S. (2011). Overtraining during preseason: stress and negative affective states among professional rugby union players. Journal of Clinical Sport Psychology, 5, 211-222.

Peluso, M.A.M., \& de Andrade, L.H.S. (2005). Physical activity and mental health: the association between exercise and mood. Clinic, 60(1), 61-70. 
Pensguard, A.M., \& Roberts, G.C. (2000). The relationship between motivational climate, perceived ability and sources of distress among elite athletes. Journal of Sports Sciences, 8(3), 183-189.

Plateau, C.R., McDermott, H.J., Arcelus, J., \& Meyer, C. (2014). Identifying and preventing disordered eating among athletes: perceptions of track and field coaches. Psychology of Sport and Exercise, 15, 721-728. doi.org/10.1016/j.psychsport.2013.11.004

Plymouth, B. (2012). Gender difference within equestrian sports: an issue of difference and inequality. Sport in Society, 15(3), 335-348.

Pummell, B., Harwood, C., \& Lavallee, D. (2008). Jumping to the next level: a qualitative examination of within-career transition in adolescent event riders. Psychology of Sport and Exercise, 9(4), 427-447. doi.org/10.1016/j.psychsport.2007.07.004

Reardon, C.L., \& Factor, R.M. (2010). A systemic review of diagnosis and medical treatment of mental illness in athletes. Sports Medicine, 40(11), 961-980. doi: $10.2165 / 11536580$

Rice, S.M., Purcell, R., De Silva, S., Mawren, D., McGorry, P.D., \& Parker, A.G. (2016). The mental health of elite athletes: a narrative systematic review. Sports Medicine, doi:10.1007/s40279-016-0492-2

Rice, S.R., Parker, A.G., Rosenbaum, S., Bailey, A., Mawren, D., \& Purcell, R. (2018). Sport-related concussion and mental health outcomes in elite athletes: a systematic review. Sports Medicine, 48(2), 447-465.

Schultz, P.N., Remick-Barlow, G.A., \& Robbins, L. (2007). Equine-assisted psychotherapy: a mental health promotion/intervention modality for children 
who have experienced intra-family violence. Health and Social Care in the Community, 15(3), 265-271. doi.org/10.1111/j.1365-2524.2006.00684.x

Shanmugam ,V., Jowett, S., \& Meyer, C. (2013). Eating psychopathology amongst athletes: the importance of relationships with parents, coaches and teammates. International Journal of Sport and Exercise Psychology, 11, 24-38.

Shanmugam, V., Jowett, S., \& Meyer, C. (2011). Application of the transdiagnositc cognitive-behavioural model of eating disorders to the athletic population, Journal of Clinical Sport Psychology, 5, 166-191.

Tenenbaum, G., Lloyd, M., Pretty, G., \& Hanin, Y.L. (2002). Congruence of actual and retrospective reports of precompetitive emotions in equestrians. Journal of Sport and Exercise Psychology, 24, 271 - 288. doi.org/10.1123/jsep.24.3.271

Thompson, K., \& Nesci, C. (2016). Over-riding concerns: developing safe relations in the high-risk interspecies sport of eventing. International Review for the Sociology of Sport, 51(1), 97-113. doi: 10.1177/1012690213513266

Topolovec-Vranic, J., Zhang, S., Wong, H., Lam, E., Jing, R., Russell, K. ...et al. (2015). Recognising the symptoms of mental illness following concussions in the sports community: a need for improvement. PLoS ONE 1O(11): e0141699. doi:10.1371/journal.pone.0141699

Torres-McGehee, T.M., Monsma, E.V., Gay, J.L., Minton, D.M., \& Mady-Foster, A.N. (2011). Prevalence of eating disorder risk and body image distortion among national collegiate athletic association division I varsity equestrian athletes. Journal of Athletic Training, 46(4), 431-437. doi.org/10.4085/1062$6050-46.4 .431$ 
600 Vamplew, W. (2012). Bulimic practices and alcohol consumption: performance

601 enabling performance enhancing mechanisms in nineteenth-century British sport. Performance Enhancement \& Health, 1, 51-54.

603 Wolframm, I., Shearman , J., \& Micklewright, D. (2010). A preliminary investigation into mood states of advanced and novice dressage riders prior to competition. Journal of Veterinary Behaviour: Clinical Application and Research, 5, 211. 